\title{
ESTIMASI HARGA MULTI-STATE EUROPEAN CALL OPTION MENGGUNAKAN MODEL BINOMIAL
}

\author{
Mila Kurniawaty ${ }^{1}$ dan Endah Rokhmati ${ }^{2}$ \\ ${ }^{1}$ Jurusan Matematika, Universitas Brawijaya, Malang. \\ email: mila akuwni@yahoo.com \\ ${ }^{2} J u r u s a n$ Matematika, Institut Teknologi Sepuluh Nopember, Surabaya
}

\begin{abstract}
ABSTRAK
Option merupakan kontrak yang memberikan hak kepada pemiliknya untuk membeli (call option) atau menjual (put option) sejumlah aset dasar tertentu (underlying asset) dengan harga tertentu (strike price) dalam jangka waktu tertentu (sebelum atau saat expiration date). Perkembangan option belakangan ini memunculkan banyak model pricing untuk mengestimasi harga option, salah satu model yang digunakan adalah formula Black-Scholes. Multi-state option merupakan sebuah option yang payoff-nya didasarkan pada dua atau lebih aset dasar. Ada beberapa metode yang dapat digunakan dalam mengestimasi harga call option, salah satunya masyarakat finance sering menggunakan model binomial untuk estimasi berbagai model option yang lebih luas seperti multi-state call option. Selanjutnya, dari hasil estimasi call option dengan model binomial didapatkan formula terbaik berdasarkan penghitungan eror dengan mean square error. Dari penghitungan eror didapatkan eror rata-rata dari masing-masing formula pada model binomial. Hasil eror rata-rata menunjukkan bahwa estimasi menggunakan formula 5 titik lebih baik dari pada estimasi menggunakan formula 4 titik.
\end{abstract}

Kata kunci: option, formula Black-Scholes, multi-state option, model binomial.

\section{PENDAHULUAN}

Perkembangan dunia perekonomian sekarang ini semakin pesat, seiring dengan kebutuhan masyarakat yang terus meningkat sehingga mendorong para pelaku ekonomi termasuk para investor untuk bersaing memperoleh keuntungan semaksimal mungkin. Dengan membayar sejumlah uang tertentu untuk investasi awal, investor dapat menguasai saham yang nilainya berlipat ganda dari investasi awal. Oleh karena itu, diperlukan alat investasi yang berupa option.

Pada dasarnya, option merupakan kontrak yang memberikan hak kepada pemiliknya untuk membeli atau menjual sejumlah aset dasar tertentu dengan harga tertentu (strike price) dalam jangka waktu tertentu. Aset dasarnya dapat berupa saham, kurs, indeks, atau komoditas. Menurut waktu exercise-nya, ada beberapa jenis option. Salah satunya adalah European option, yang hanya dapat di-exercise pada saat jatuh tempo.

Jika sebuah option yang payoff-nya berdasarkan pada dua atau lebih aset dasar maka dinamakan multi-state option. Model binomial paling banyak digunakan dalam komunitas finance untuk estimasi berbagai model option yang lebih luas seperti pada multi-state European option

Dalam mengkaji mengenai estimasi harga multi-state European call option menggunakan model binomial, akan diperoleh suatu pemahaman yang mendalam mengenai estimasi tersebut dan menjadi alternatif lain bagi komunitas finance, khususnya para investor untuk mengestimasi harga option di samping modelmodel lain yang telah ada agar dapat memaksimumkan keuntungan dan meminimumkan kerugian.

\section{PENDEKATAN PROSES RETURN}

Dalam mengestrimasi harga multi-state European call option dengan model binomial digunakan suatu pendekatan proses return. Dalam melakukan pendekatan proses return diperlukan pemahaman mengenai fungsi payoff dan formula Black-Scholes.

\section{Fungsi payoff}

Berdasarkan waktu exercise-nya, ada beberapa jenis option. Salah satunya adalah European option, yang hanya dapat di-exercise pada saat jatuh tempo.

Fungsi payoff dari European call option adalah sebagai berikut

$$
\text { payoff }=\max \left\{S_{T}-X, 0\right\}
$$

Atau dapat dijabarkan sebagai berikut

$$
\text { payoff }=\left\{\begin{array}{l}
S_{T}-X, \text { jika } S_{T}>X \\
0, \text { jika } S_{T} \leq X
\end{array}\right.
$$

dimana $S_{T}$ adalah stock price pada saat jatuh tempo dan $X$ adalah strike price. 


\section{Formula Black-Scholes untuk European option}

Persamaan Black-Scholes dari option pricing adalah sebagai berikut

$$
\frac{\partial c}{\partial \tau}+\frac{\sigma^{2}}{2} S^{2} \frac{\partial^{2} c}{\partial S^{2}}+r S \frac{\partial c}{\partial S}-r c=0
$$

Berdasarkan asumsi model Black-Scholes pada persamaaan (1), persamaan Black-Scholes untuk European vanilla call option dapat dibentuk sebagai berikut

$$
\frac{\partial c}{\partial \tau}=\frac{\sigma^{2}}{2} S^{2} \frac{\partial^{2} c}{\partial S^{2}}+r S \frac{\partial c}{\partial S}-r c,-\infty<S<\infty, \tau>0
$$

dimana $c=c(S, \tau)$ merupakan nilai European call option, $S$ adalah harga aset dasar, $\tau$ adalah jatuh tempo, $r$ adalah suku bunga bebas resiko dan $\sigma$ adalah volatilitas.

Kondisi awal (payoff saat jatuh tempo) dapat dinyatakan sebagai berikut

$$
c(S, 0)=\max \{S-X, 0\}
$$

dengan $X$ adalah strike price.

Solusi dari persamaan (2) diperoleh sebagai berikut

$c(S, \tau)=$

$e^{-r \tau} \int_{0}^{\infty} \max \left(S_{T}-X\right) \frac{1}{S_{\tau} \sigma \sqrt{2 \pi \tau}} \exp \left(-\frac{\left\{\ln S_{T}-\left[\ln S+\left(r-\frac{\sigma^{2}}{2}\right) \tau\right]\right\}^{2}}{2 \sigma^{2} \tau}\right) d S_{T}$

Operasi ekspektasi

$$
c(S, \tau)=E\left(\max \left(S_{T}-X, 0\right)\right) e^{-r(T-t)}
$$

dapat dinyatakan sebagai berikut

$$
\begin{aligned}
c(S, \tau) & =e^{-r(T-t)} \int_{0}^{\infty} \max \left(S_{T}-X\right) \psi\left(S_{T} ; S\right) d S_{T} \\
\text { dengan } \tau & =T-t .
\end{aligned}
$$

$\psi\left(S_{T} ; S\right)$ merupakan transition density function dari harga aset $S_{T}$ yang dapat dinyatakan sebagai berikut

$$
\psi\left(S_{T} ; S\right)=\frac{1}{S_{\tau} \sigma \sqrt{2 \pi \tau}} \exp \left(-\frac{\left\{\left(\ln S_{T}-\ln S\right)-\left(r-\frac{\sigma^{2}}{2}\right) \tau\right\}^{2}}{2 \sigma^{2} \tau}\right)
$$

Dari persamaan tersebut terlihat bahwa fungsi densitas berdistribusi normal dengan variabel $\ln \frac{S_{T}}{S}$, yang mempunyai mean $\left(r-\frac{\sigma^{2}}{2}\right) \tau$ dan varians $\sigma^{2} \tau$.

Model yang digunakan adalah two-state option dan densitas bersama dari harga dua aset dasar $S_{1}$ dan $S_{2}$ adalah lognormal bivariate.

Dalam dunia netral resiko, return aset dasar diberikan sebagai berikut

$$
\ln \frac{s_{i}^{\Delta t}}{s_{i}}=\zeta_{i}, \mathrm{i}=1,2
$$

dimana $S_{i}$ merupakan harga dari aset dasar $i$ pada saat ini, $S_{i}^{\Delta t}$ merupakan harga aset dasar $i$ pada suatu periode $\Delta t$ berikutnya dan $\zeta_{i}$ adalah return aset dasar.
Sesuai perhitungan pada (4), variabel acak normal $\zeta_{i}$ mempunyai mean $\left(r-\frac{\sigma_{i}^{2}}{2}\right) \Delta t$ dan varians $\sigma_{i}^{2} \Delta t$.

dimana $r$ adalah tingkat bunga bebas resiko dan $\sigma^{2}$ adalah varians dari proses lognormal.

$\rho$ merupakan koefisien korelasi antara $\zeta_{1}$ dan $\zeta_{2}$ dan $\sigma_{i}$ adalah volatilitas harga aset dasar $S_{i, i}=1,2$.

Proses normal bivariate bersama $\left\{\zeta_{1}, \zeta_{2}\right\}$ didekati oleh sepasang variabel acak diskrit $\left\{\zeta_{1}^{a}, \zeta_{2}^{a}\right\}$ dengan mengikuti distribusi berikut

Tabel 1. Distribusi variabel diskrit $\left\{\zeta_{1}^{a}, \zeta_{2}^{a}\right\}$

\begin{tabular}{ccc}
\hline$\zeta_{1}^{a}$ & $\zeta_{2}^{a}$ & probabilitas \\
\hline$v_{1}$ & $v_{2}$ & $p_{1}$ \\
$v_{1}$ & $-v_{2}$ & $p_{2}$ \\
$-v_{1}$ & $-v_{2}$ & $p_{3}$ \\
$-v_{1}$ & $v_{2}$ & $p_{4}$ \\
0 & 0 & $p_{5}$ \\
\hline
\end{tabular}

dimana $v_{i}=\lambda_{i} \sigma_{i} \sqrt{\Delta t}, i=1,2$.

\section{HASIL DAN PEMBAHASAN}

\section{Nilai Probabilitas}

Untuk mendapatkan nilai probabilitas $p_{1}, p_{2}, p_{3}, p_{4}$ dan $p_{5}$, mean, varian, dan covarian dari $\left\{\zeta_{1}^{a}, \zeta_{2}^{a}\right\}$ disamakan dengan $\left\{\zeta_{1}, \zeta_{2}\right\}$. Sehingga didapatkan persamaan yang bersesuaian sebagai berikut

$$
\begin{aligned}
& E\left(\zeta_{1}^{a}\right)=v_{1}\left(p_{1}+p_{2}-p_{3}-p_{4}\right)=\left(r-\frac{\sigma_{1}^{2}}{2}\right) \Delta t \\
& E\left(\zeta_{2}^{a}\right)=v_{2}\left(p_{1}-p_{2}-p_{3}+p_{4}\right)=\left(r-\frac{\sigma_{2}^{2}}{2}\right) \Delta t \\
& \operatorname{var}\left(\zeta_{1}^{a}\right)=v_{1}^{2}\left(p_{1}+p_{2}+p_{3}+p_{4}\right)=\sigma_{1}^{2} \Delta t \\
& \operatorname{var}\left(\zeta_{2}^{a}\right)=v_{2}^{2}\left(p_{1}+p_{2}+p_{3}+p_{4}\right)=\sigma_{2}^{2} \Delta t \\
& \operatorname{cov}\left(\zeta_{1}^{a}, \zeta_{2}^{a}\right)=v_{1} v_{2}\left(p_{1}-p_{2}+p_{3}-p_{4}\right)=\sigma_{1} \sigma_{2} \rho \Delta t
\end{aligned}
$$

Agar persamaan (5) dan (6) konsisten, harus ditentukan $\lambda=\lambda_{1}=\lambda_{2}$ sehingga diperoleh empat persamaaan independen untuk lima nilai probabilitas sebagai berikut

$$
\begin{aligned}
& p_{1}+p_{2}-p_{3}-p_{4}=\frac{\left(r-\frac{\sigma_{1}^{2}}{2}\right) \sqrt{\Delta t}}{\lambda \sigma_{1}} \\
& p_{1}-p_{2}-p_{3}+p_{4}=\frac{\left(r-\frac{\sigma_{2}^{2}}{2}\right) \sqrt{\Delta t}}{\lambda \sigma_{2}} \\
& p_{1}+p_{2}+p_{3}+p_{4}=\frac{1}{\lambda^{2}} \\
& p_{1}-p_{2}+p_{3}-p_{4}=\frac{\rho}{\lambda^{2}}
\end{aligned}
$$

Karena jumlahan probabilitas harus sama dengan satu, maka diberikan kondisi berikut

$$
p_{1}+p_{2}+p_{3}+p_{4}+p_{5}=1
$$


Sehingga didapatkan penyelesaian persamaan tersebut dan diperoleh nilai masing-masing probabilitas yang terjadi

$$
\begin{aligned}
& p_{1}=\frac{1}{4}\left[\frac{1}{\lambda^{2}}+\frac{\sqrt{\Delta t}}{\lambda}\left(\frac{r-\frac{\sigma_{1}^{2}}{2}}{\sigma_{1}}+\frac{r-\frac{\sigma_{2}^{2}}{2}}{\sigma_{2}}\right)+\frac{\rho}{\lambda^{2}}\right] \\
& p_{2}=\frac{1}{4}\left[\frac{1}{\lambda^{2}}+\frac{\sqrt{\Delta t}}{\lambda}\left(\frac{r-\frac{\sigma_{1}^{2}}{2}}{\sigma_{1}}-\frac{r-\frac{\sigma_{2}^{2}}{2}}{\sigma_{2}}\right)-\frac{\rho}{\lambda^{2}}\right] \\
& p_{3}=\frac{1}{4}\left[\frac{1}{\lambda^{2}}+\frac{\sqrt{\Delta t}}{\lambda}\left(-\frac{r-\frac{\sigma_{1}^{2}}{2}}{\sigma_{1}}-\frac{r-\frac{\sigma_{2}^{2}}{2}}{\sigma_{2}}\right)+\frac{\rho}{\lambda^{2}}\right] \\
& p_{4}=\frac{1}{4}\left[\frac{1}{\lambda^{2}}+\frac{\sqrt{\Delta t}}{\lambda}\left(-\frac{r-\frac{\sigma_{1}^{2}}{2}}{\sigma_{1}}+\frac{r-\frac{\sigma_{2}^{2}}{2}}{\sigma_{2}}\right)-\frac{\rho}{\lambda^{2}}\right] \\
& p_{5}=1-\frac{1}{\lambda^{2}},
\end{aligned}
$$

dengan $\lambda \geq 1$ adalah parameter bebas.

\section{Estimasi Harga Multi-state European Call Option Menggunakan Model Binomial.}

Dalam model binomial, perubahan harga saham tiap periode dari interval waktu $\Delta t$ diasumsikan mempunyai dua kemungkinan hasil, yaitu $u$ dengan probabilitas $p$ dan $d$ dengan probabilitas $1-p(u>d)$ seperti pada gambar berikut

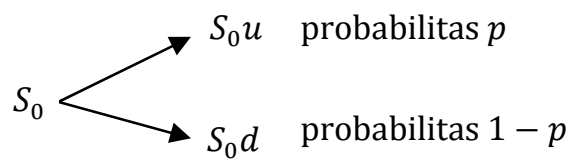

Gambar 1. Kontruksi pohon binomial

Jika harga saham (stock option) saat ini $S_{0}$, maka harga saham pada saat $t$ adalah sebagai berikut

$$
S_{t}=S_{0} u^{n} d^{t-n}, t=1,2, \ldots, T
$$

dimana $0<d<1<u$ dan $n=0,1, \ldots, t$.

Harga call saat ini dinotasikan dengan $c$, dan $c_{u}^{\Delta t}$ dan $c_{d}^{\Delta t}$ menunjukkan harga call setelah satu periode (waktu jatuh tempo dalam konteks sekarang) yang bersesuaian dengan pergerakan naik dan turunnya harga aset, Misal $X$ menyatakan strike price dari call, maka payoff dari call pada saat jatuh tempo adalah sebagai berikut

$\left\{c_{u}^{\Delta t}=\max (u S-X, 0)\right.$ dengan probabilitas $p$

$\left\{c_{d}^{\Delta t}=\max (d S-X, 0)\right.$ dengan probabilitas $1-p$ berikut

Nilai terkini dari call diberikan sebagai

$$
\begin{array}{r}
c=\frac{p c_{u}^{\Delta t}+(1-p) c_{d}^{\Delta t}}{R} \\
\text { dengan } p=\frac{R-d}{u-d} \operatorname{dan} R=e^{r \Delta t} .
\end{array}
$$

Jika $S$ dan $S_{\Delta t}$ menyatakan harga aset saat ini dan harga aset satu periode setelah $\Delta t$, maka mean dan varians dari $\frac{s_{\Delta t}}{s}$ adalah

dan

$$
p u+(1-p) d
$$

$$
p u^{2}+(1-p) d^{2}-[p u+(1-p) d]^{2} \text {. }
$$

Dengan derajat akurasi $O(\Delta t)$ nilai dari parameter $u$ dan $d$ adalah $u=e^{\sigma \sqrt{\Delta t}}$ dan $d=e^{-\sigma \sqrt{\Delta t}}$

Karena terdapat dua aset dasar yang mendasari harga European call option yaitu $S_{1}$ dan $S_{2}$, maka kemungkinan yang terjadi dapat digambarkan sebagai berikut
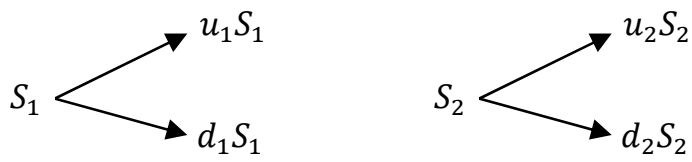

Gambar 2. Kontruksi pohon binomial dua aset dasar

Jika $S_{i}, i=1,2, \ldots, n$ menyatakan harga aset dasar $i$ dan $V\left(S_{1}, S_{2}, \ldots, S_{n}, T\right)$ menyatakan nilai dari sekuritas derivatif, maka secara umum fungsi payoff-nya dinyatakan sebagai fungsi linier berikut

$$
V(S, 0)=\max \left(\sum_{i=1}^{n} a_{i} S_{i}+b, 0\right)
$$

dimana $b$ dan $a_{i}, i=1,2, \ldots, n$ adalah konstanta.

Dengan menggunakan fungsi payoff untuk multi-state option pada (8) dan persamaan (7), maka dapat dijabarkan sebagai berikut

$\left\{\begin{array}{l}c_{u_{1} u_{2}}^{\Delta t}=\max \left(u_{1} S_{1}+u_{2} S_{2}-X, 0\right), \text { dengan peluang } p_{1} \\ c_{u_{1} d_{2}}^{\Delta t}=\max \left(u_{1} S_{1}+d_{2} S_{2}-X, 0\right) \text {, dengan peluang } p_{2} \\ c_{d_{1} d_{2}}^{\Delta t}=\max \left(d_{1} S_{1}+d_{2} S_{2}-X, 0\right), \text { dengan peluang } p_{3} \\ c_{d_{1} u_{2}}^{\Delta t}=\max \left(d_{1} S_{1}+u_{2} S_{2}-X, 0\right) \text {, dengan peluang } p_{4} \\ c_{0,0}^{\Delta t}=\max \left(S_{1}+S_{2}-X, 0\right), \text { dengan peluang } p_{5}\end{array}\right.$ dengan $u_{i}=e^{v_{i}}, d_{i}=e^{-v_{i}}, i=1,2$.

Sehingga menurut formula binomial, diperoleh harga dari multi-state call option sebagai berikut

$c=\frac{p_{1} c_{u_{1} u_{2}}^{\Delta t}+p_{2} c_{u_{1} d_{2}}^{\Delta t}+p_{3} c_{d_{1} d_{2}}^{\Delta t}+p_{4} c_{d_{1} u_{2}}^{\Delta t}+p_{5} c_{0,0}^{\Delta t}}{R}$

Jika $\lambda=1$, maka $p_{5}=0$ dan formula 5 titik berkurang menjadi 4 titik sebagai berikut

$c=\frac{p_{1} c_{u_{1} u_{2}}^{\Delta t}+p_{2} c_{u_{1} d_{2}}^{\Delta t}+p_{3} c_{d_{1} d_{2}}^{\Delta t}+p_{4} c_{d_{1} u_{2}}^{\Delta t}}{R}$

dimana $R=e^{r \Delta t}$.

\section{Simulasi untuk Mengestimasi Harga Option}

Hasil estimasi call option dengan model binomial dengan $\sigma_{1}=0.2$ dan $\sigma_{2}=0.3$, untuk $\lambda$ bernilai 1.0 sampai 2.0 dapat digambarkan sebagai berikut: 


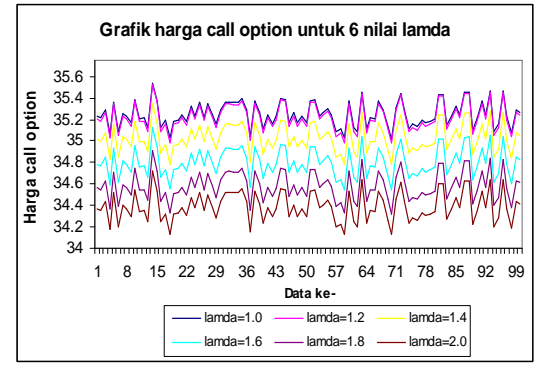

Gambar 3. Grafik Call Option Model Binomial untuk beberapa nilai lamda

Dari grafik terlihat bahwa pertambahan nilai $\lambda$ menurunkan harga call option. Hal ini berarti, penggunaan formula 5 titik dapat menurunkan harga call option dari pada formula 4 titik.

\section{Mean Square Error (MSE)}

Penghitungan eror menggunakan Mean Square Error dituliskan sebagai berikut:

$$
R M S E=\sqrt{\frac{\sum_{n=1}^{m} \eta_{n}^{2}}{m}}
$$

dimana $\eta=$ market option price - model option price.

Error dari model binomial berdasarkan Mean Square Error sesuai penghitungan apabila ditampilkan dalam grafik sebagai berikut

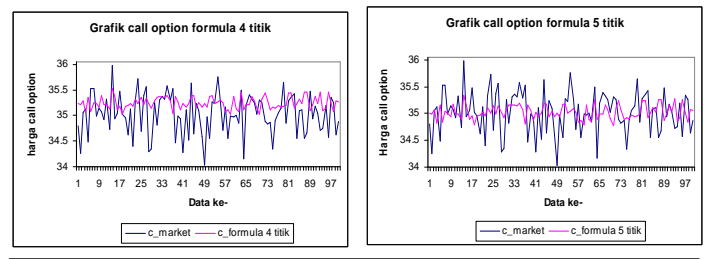

MSE formula 4 titik dan 5 titik

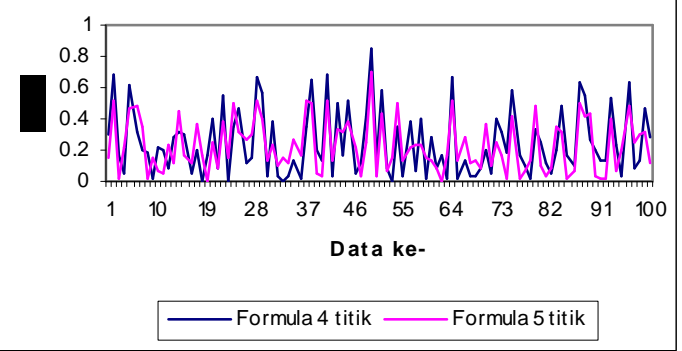

Gambar 4. Grafik harga call dan mean square error model binomial formula 4 titik dan 5 titik

Dari hasil penghitungan eror menggunakan Mean Square Error didapatkan rata-rata eror sebagai berikut:

Tabel 2. Tabel hasil average MSE dari model binomial 4 titik dan 5 titik

\begin{tabular}{cc}
\hline Model Binomial & Average MSE \\
\hline Formula 4 titik & 0.244817 \\
Formula 5 titik & 0.2271071 \\
\hline
\end{tabular}

Berdasarkan hasil penghitungan eror dari dua formula pada model binomial dapat disimpulkan bahwa formula 5 titik mempunyai eror yang lebih kecil daripada formula 4 titik . Oleh karena itu Formula 5 titik pada model binomial dapat dinyatakan sebagai formula yang yang lebih baik daripada formula 4 titik.

\section{PENUTUP}

Berdasarkan hasil pembahasan mengenai estimasi harga multi-state European call option dengan model binomial dapat disimpulkan bahwa estimasi harga multi-state European call option dengan model Binomial diperoleh dengan pendekatan proses return yang mempunyai variabel acak normal didekati dengan sepasang variabel acak diskrit untuk mendapatkan nilai probabilitas yang terjadi pada masing-masing aset dasar sehingga dapat diestimasi menggunakan model binomial.

Estimasi harga multi-state European call option menggunakan model binomial diperoleh dua formula, yaitu:

1. Formula 5 titik

$$
c=\frac{p_{1} c_{u_{1} u_{2}}^{\Delta t}+p_{2} c_{u_{1} d_{2}}^{\Delta t}+p_{3} c_{d_{1} d_{2}}^{\Delta t}+p_{4} c_{d_{1} u_{2}}^{\Delta t}+p_{5} c_{0,0}^{\Delta t}}{R}
$$

2. Formula 4 titik

$$
c=\frac{p_{1} c_{u_{1} u_{2}}^{\Delta t}+p_{2} c_{u_{1} d_{2}}^{\Delta t}+p_{3} c_{d_{1} d_{2}}^{\Delta t}+p_{4} c_{d_{1} u_{2}}^{\Delta t}}{R}
$$

Formula terbaik dalam model binomial pada multi-state option adalah formula 5 titik karena mempunyai eror rata-rata yang lebih kecil daripada formula 4 titik.

Dari hasil simulasi dapat dilihat bahwa estimasi harga multi-state European call option menggunakan model binomial sangat dipengaruhi oleh besarnya suatu parameter bebas $\boldsymbol{\lambda}$. Semakin tinggi nilai $\boldsymbol{\lambda}$ maka harga dari call option akan semakin turun.

\section{DAFTAR PUSTAKA}

[1] Kwok, Yue-Kuen. 1998. Mathematical Models of Financial Derivatives. Singapore: Springer.

[2] Pliska, R. Stanley. 1997. Introduction toMathematical Finance: Discrete Time Model. Oxford: Blackwell.

[3] Bodie, Kane, Marcus. 2005. Investment. Sixth Edition. McGraw-Hill, International Edition.

[4] Sembel, Roy, dan Fardiansyah, Tedy. 2002. Sekuritas Derivatif: Madu atau Racun. Jakarta: Salemba empat. 
[5] Rudiger, Seydel. 2002. Tools for Computational Finance. Koln: Springer.

[6] Higham, Desmond J. 2004. An Introduction to Financial Option Valuation: Mathematics, Stochastics, and Computation. Cambridge: Cambridge University Press.

[7] Rahayu, S.K.T. 2006. Estimasi Nilai European Call Option Menggunakan Metode Historical Data dan Filter Kalman. Skripsi ITS Surabaya.
[8] Hull, John C. 2002. Option Future and Other Derivatives. New Jersey: Prentice Hall.

[9] Ross, Sheldon M. 2004. An Introduction to Mathematical Finance: Options and Other Topics. Cambridge: Cambridge University Press. 